\title{
Luffa cylindrica (L.) M. Roemer (Sponge Gourd-Niyan wetakolu): An Emerging High Potential Underutilized Cucurbit
}

\author{
M.W.K.P. Silva, R.H.G. Ranil ${ }^{1}$ and R.M. Fonseka ${ }^{1 *}$ \\ Postgraduate Institute of Agriculture \\ University of Peradeniya \\ Sri Lanka
}

\begin{abstract}
Luffa cylindrica (L.) M. Roem (Sponge gourd, Niyan wetakolu) is an emerging high potential crop in Asia. In Sri Lanka, it is considered as an underutilized vegetable. Although the crop has been cultivated in both dry and intermediate zones of Sri Lanka for a long time, little information is available on the morphology, floral biology, growth and yield performance of the crop under these conditions. Therefore, this study was carried out to evaluate the growth and yield performances under different trellising methods, floral biology, sponge yield, and pest and disease occurrence of sponge gourd using scientifically accepted methods. Three types of trellising were tested to optimize the final yield. The results revealed that horizontal type trellising is ideal for cultivation of sponge gourd and the average yield was 8.4 t/ha under existing environmental conditions. There were no significant differences in fruit length and diameter among different trellising methods. However, the fruit number differed significantly among those trellising methods. Floral biology, pest and diseases occurrence and ethnobotanical uses of sponge gourds were also documented. These data may provide baseline information for future studies on yield improvement, variety development and subsequent development of agronomic package for cultivation of sponge gourd. It is recommended to repeat this study for another 2-3 seasons, while initiating concurrent studies on fiber quality to exploit industrial and export potential.
\end{abstract}

Key words: Floral biology, Luffa cylindrica, Trellising method, Yield performance

\section{INTRODUCTION}

Luffa is a tropical and subtropical vegetable belongs to the family Cucurbitaceae, which produces fruit containing fibrous vascular system. The crop has a long history of cultivation in the tropical countries of Asia and Africa (Oboh \& Aluyor, 2009). Luffa acutangula (L.) Roxb. and Luffa cylindrica (L.) M. Roem are the only domesticated species in the genus and most common and popular. L. cylindrica is commonly called as sponge gourd (Niyan wetakolu in Sinhala) and widely grown in tropical Asia and China. It tolerates a wide range of climatic and soil conditions, although excessive rainfall during flowering and fruiting period can cause damage to the yield (Bal et al., 2004). China, Korea, India, Japan and Central America are the main commercial producers of $L$. cylindrica. Use of luffa sponges for personal hygiene and household cleaning is common in many countries. In the developed world, the demand for luffa sponge products for skin care is increasing. Many environmentally conscious consumers appreciate that luffa products are biodegradable, natural and a renewable resource (Davis \& DeCourley, 1993). Oboh and Aluyor (2009) have summarized the worldwide use of sponge gourd in agriculture, medicine, environmental

\footnotetext{
Department of Crop Science, Faculty of Agriculture, University of Peradeniya, Peradeniya, Sri Lanka

Author for correspondence: ramyaf@gmail.com
} 
engineering and biotechnology including food and industrial purposes; viz. bathroom sponge, component of shock absorbers, sound proof linings, utensils cleaning sponge, packing materials, making crafts, filters in factories, bio diesel and chemical extractions. Recent data suggest that commercial cultivation of the crop is increasing in Asian countries due to its increasing economic importance (Oboh \& Aluyor, 2009).

Sponge gourd is fast becoming an indispensable crop due to its wide industrial applications. The potential and industrial applications of sponge gourd highlighted by Boynard and D'Almeida (1999), Bal et al. (2004) and Demir et al. (2008) and now it is becoming a highly demanding natural fiber worldwide. Luffa sponge is a suitable natural matrix for immobilization of microorganisms and has been successful in the process of biosorption of heavy metals from wastewater. Therefore, it is vital to explore the potential of sponge to develop as natural fiber and contribute to the industry as well as to the export market.

Isolated cultivations sponge gourd are found in Chena cultivations and homegardens in dry and intermediate zones of Sri Lanka. Hence, the crop is considered as an underutilized vegetable and rarely used for medicinal purpose. Its' use as a bathroom sponge is common among rural communities. Though the economic importance of this lesser known vegetable has not been recognized in Sri Lanka, it is well known world wide. However, the information on morphology, reproductive biology, agronomy and yield potential of sponge gourd under local condition is scarce. Lack of such information could be considered as a major obstacle to develop and popularize this nutritionally as well as industrially important crop in the country.

In Sri Lanka, farmers do not follow proper management practices for growing sponge gourd and they do not provide trellising for sponge gourd as they practice for luffa, which is a similar kind of vegetable extensively grown in the area. Usually they allow plants to trail along fences or rarely trellis to big trees. Though the vine can be left to grow prostrate on the ground, yield and fruit quality are affected. By using a support structure or trellis fruit yield could be increased and the quality would be improved. Therefore, this study was carried out to evaluate the growth and yield performance, floral biology, sponge yield, and pest and disease occurrence of sponge gourd under different trellising methods. This preliminary study will provide basic information for further studies on development of agronomic package, and improvement of yield through varietal development and breeding programmes of $L$. cylindrica. The ultimate objective of this study was to promote sponge gourd as a vegetable and to explore the possibilities of commercial production of fibrous sponge as a raw material for industries.

\section{MATERIALS AND METHODS}

The study was conducted at Rajanganaya Right Bank, Angamuwa area during the wet season (Maha) 2010/2011. The area belongs to Low Country Dry zone $\left(\mathrm{DL}_{1 \mathrm{~b}}\right)$ region and it has a distinct bimodal rainfall pattern. The average annual maximum and minimum temperatures are $30{ }^{\circ} \mathrm{C}$ and $21{ }^{\circ} \mathrm{C}$, respectively. The relative humidity is around $78 \%$ and solar radiation is about 10-11 h/day. The experiment was laid as a Randomized Complete Block Design (RCBD) with three replicates. Three types of trellising methods were considered as treatments [vertical $\left(\mathrm{T}_{1}\right)$, horizontal $\left(\mathrm{T}_{2}\right)$ and inverted "V" shape $\left(\mathrm{T}_{3}\right)$ ]. Three to four seeds per planting hole were planted at a spacing of $1.5 \mathrm{~m} \times 1.5 \mathrm{~m}$ and later thinned out to two plants per hole. All the agronomic practices such as fertilizer recommendation, irrigation, weeding and pest and disease control were followed according to the recommendations for $L$. 
acutangula recommended by the Department of Agriculture, Sri Lanka. From flower bud initiation until fruit formation, all the biological events of flowers were observed and recorded. Number of fruits per vine, pod length, pod diameter, fresh weight of pods, sponge weight, seed weight and number of seeds per pod, male to female flower ratio were recorded. Sponge yield was also obtained by using traditional fiber extraction method practiced by the farmers in the area (Personal communication). Data were analysed using Statistical Analysis System (SAS) computer software, through ANOVA procedure. Mean separation was done according to LSD (Least Significant Difference) method.

\section{RESULTS AND DISCUSSION}

Different types of trellising methods were tested for sponge gourd in various countries and those are performed differently due to the other factors that affected the yield. However, number of fruits and total yield of this study showed significant difference $(\mathrm{P}<0.05)$ among three trellising methods used. The highest number of fruits and yield was recorded with horizontal trellising $\left(\mathrm{T}_{2}\right)$ (Plate 1C) while the lowest number of fruits and yield was showed by vertical trellising $\left(T_{1}\right)$ (Figs. $1 \& 2$ ). The average fruit yield was $8.4 \mathrm{t} /$ ha under the existing environmental conditions. There was no significant difference in fruit length $(18.09 \pm 1.01$ $\mathrm{cm})$ and diameter $(4.51 \pm 0.3 \mathrm{~cm})$ among treatments. But, fruit number is significantly difference among three treatments and it is a determinant factor to decide the total yield.

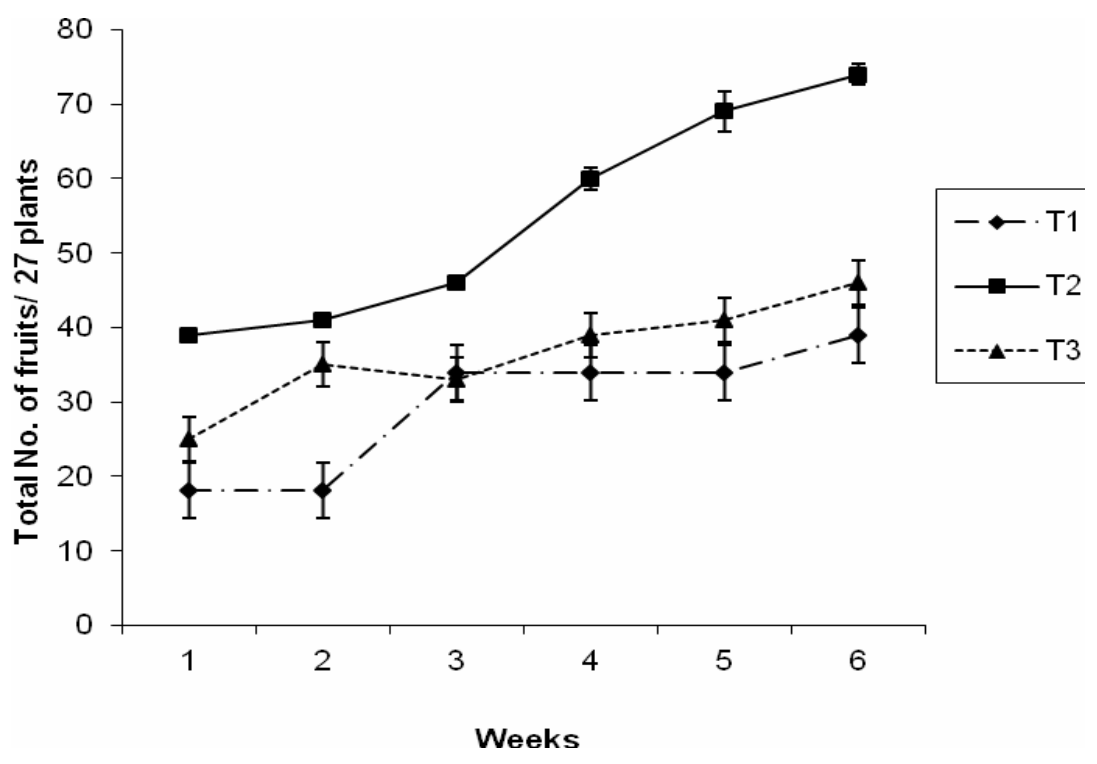

Fig. 1. Total number of fruits under three types of trellising methods 


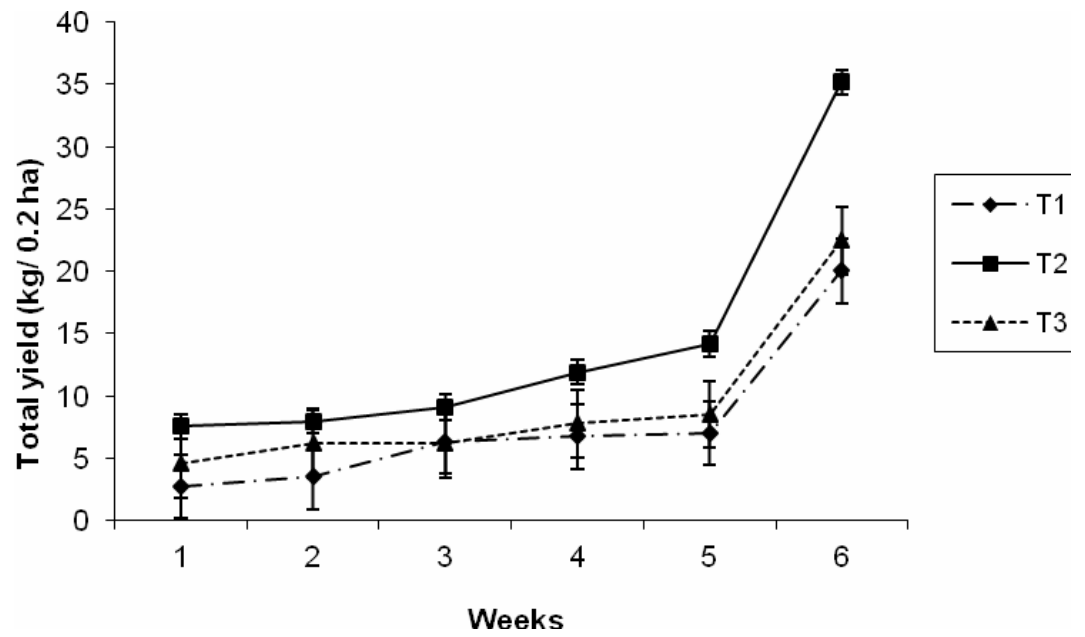

Fig. 2. Yield performance of sponge gourd under three trellising methods

Well matured sun dried fruits yielded $17-20 \mathrm{~cm}$ long sponges with densely arranged fibers and average sponge weight was $0.88 \pm 3.07 \mathrm{~g}$.

Sponge gourd is a monoecious plant (Plates 1 A \& B) and flowering started 6-7 weeks after seeding. Initially, only male flowers were observed. Floral biology and reproductive events of sponge gourd has studied by many authors and summarized by Oboh and Aluyor (2009). Many of reproductive events observed during this study were also closely match with the previous observation recorded by other researches. In this study, it was able to record male to female flower ratio as 20:1, which is considered to be uneconomical as far as the yield is concerned. It is a well known fact that, changes of microclimatic influenced the reproductive biology of any plant. Thus, it is suggested to continue this study for another 2-3 seasons to compile more accurate information on floral biology of sponge gourd under local conditions using different genotypes available in the area.
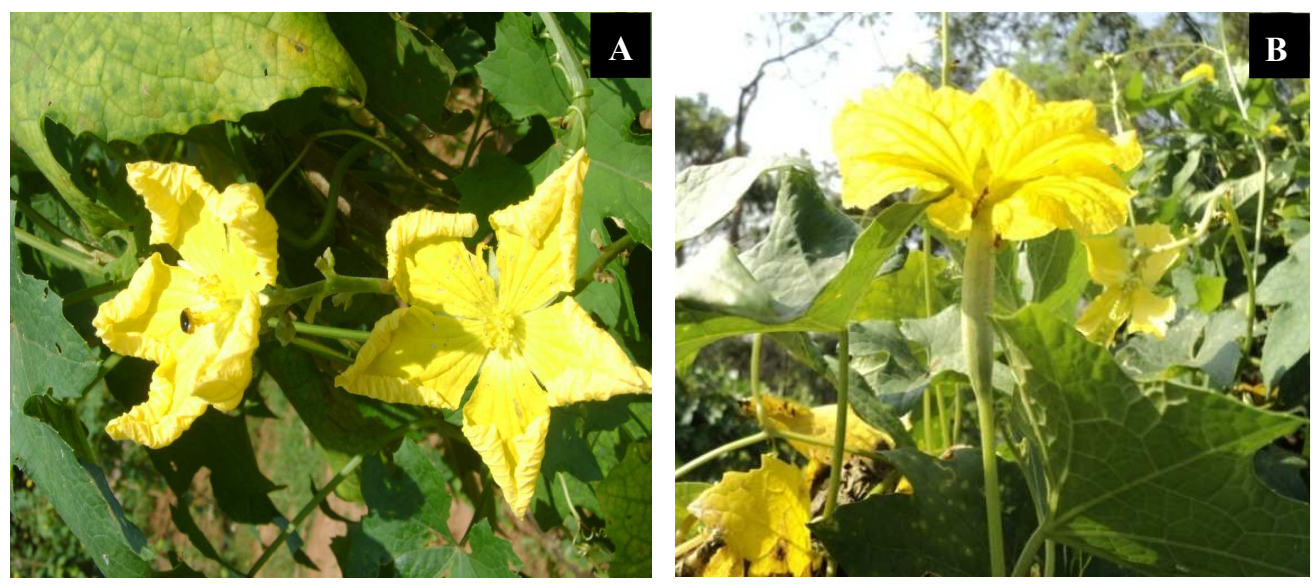

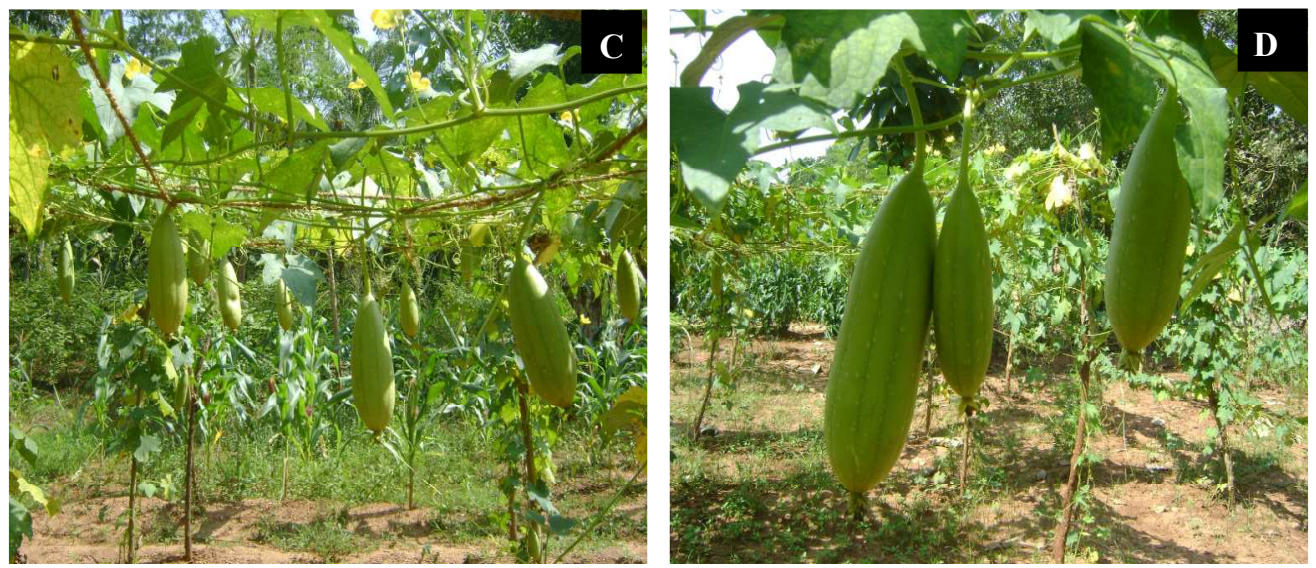

Plate 1. Flowering and fruiting of Luffa cylindrica. A. male flowers in reproductive mature stage; B. female flower 2-6 day after bud initiation; C. horizontal type trellising method; D. mature fruits

Many research findings indicate that, sponge gourd to possess resistant to pest and diseases in comparison with $L$. actangula. Observations made during the study also proved such findings. During the growing period it was observed that only 2-3 plants were affected by the leaf minor attack, but it was also a mild infection and not spread to the other plants. It is well known that luffa is severely affected by fruit fly damage and it sometime becomes a determinant factor to the final yield. In the present study, fruit fly damage was very mild and was not a detrimental factor to the final fruit yield. Such findings underscore the potential of sponge gourd to grow with minimal external inputs leading to low cost of production, qualifying it as a candidate crop for organic farming.

\section{CONCLUSIONS}

This preliminary study provides a strong base to initiate further studies on characterization, yield improvement, reproductive biology and resistance to pest and diseases of sponge gourd. Such facts provide baseline information to initiate studies on development of cultivation package, yield improvement and variety development of sponge gourds. This emerging underutilized crop will improve the livelihood of Sri Lankan farmers in the future due to its vast potential. A high possibility exists to expand the cultivations in the dry and intermediate zones of Sri Lanka as cucurbits thrive well under warm climatic conditions.

\section{REFERENCES}

Bal, K.J., Hari, B.K.C., Radha, K.T., Madhusudan, G., Bhuwon, R.S. and Madhusudan, P.U. (2004). Descriptors for Sponge Gourd [Luffa cylindrica (L.) Roem.] NARC, LIBIRD \& IPGRI.

Boynard, C.A. and D'Almeida, J.R.M. (1999). Water absorption by sponge gourd (Luffa cylindrica) -polyester composite materials, J. Mater. Sci. Lett. 18, 1789-1791. 
Demir, H., Top, A., Balköse, D. and Ulkü, S. (2008). Dye adsorption behavior of Luffa cylindrica fibers. J. Hazard Mater. 153, 389-94.

Davis, J.M. (1997). Commercial luffa sponge gourd production. Horticulture, Information Leaflet, NC State University.

Davis, J. and De Courley, C.D. (1993). Luffa sponge gourds: a potential crop for small farms. New Crops. Ed.: J. Janick and J. E. Simon. New York, Wiley: pp. 560-561.

Oboh, O. and Aluyor, E.O. (2009). Luffa cylindrica - an emerging cash crop. Af. J. of Agric. Res. 4(8), 684-688. 